\title{
Rakip ve Mahpus Romanlarında Ben ve Öteki İlişkisine Fenomenolojik Bir Bakış $^{1}$
}

\section{Seldağ BANKIR ${ }^{2}$}

\begin{abstract}
Özet
Ben ve Öteki ilişkisi düşünce tarihi boyunca başta sosyal, siyasi, hukuki olmak üzere birçok boyutta incelenen bir konudur. Önceleri konuyla ilgili düşüncelerin merkezini "Ben" kavramı oluştururken, özellikle 19. yüzyıldan itibaren Hegel'in Köle - Efendi diyalektiğiyle birlikte "Öteki" kavramı felsefi ve edebi alanda başlı başına bir inceleme konusu haline gelmiştir. 20. yüzyılın başında ortaya çıan fenomenoloji (görüngübilim) yöntemiyle birlikte Ben ve Öteki konusuyla ilgili çalışmalar da yoğunlaşmıştır. Fenomenleri yani kişinin bilincinde dolaysız olarak oluşan olgu ve olayları oluşum süreçleriyle birlikte inceleyen fenomenolojik yöntem aracıllğıyla, birçok düşünür Ben ve Öteki ilişkisini aynılık/ötekilik, içkinlik/aşkınlık, algı/duyumsama gibi kavramlar üzerinden ele almıştır.

Çalışmamızda, Fransız edebiyatından seçtiğimiz iki eser olan Emmanuel Carrère’in "Rakip" ve Marcel Proust'un "Mahpus" adl romanlarındaki Ben ve Öteki ilişkisini fenomenolojik akımın önemli iki ismi olan Edmund Husserl ve Maurice MerleauPonty'nin konuyla ilgili yaklaşımları doğrultusunda incelemeye çalıştık. Bu amaçla romanlardaki kahramanların birbirlerini karşılıklı olarak nasıl etkiledikleri, Ben’in, diğ bir deyişle Özne'nin bu ilişkide kendini ve Öteki'ni nasıl algıladı̆̆ı, Öteki'ne nasıl ulaşmaya çalıştı̆̆ gibi sorunsallar üzerinde durduk. Husserl ve Merleau-Ponty'nin bilinç, algl, duyumsama ve beden gibi kavramlar üzerinden önerdikleri kuramlardan yola çıkarak ele aldığımız romanların söyleminde Ben ve Öteki ilişkisinin nasıl oluştuğunu incelemeyi amaçlamaktayız.
\end{abstract}

Anahtar Sözcükler: Ben, öteki, fenomenoloji, roman, söylem

\section{A Phenomenological Outlook On The Relationship Between Me And The Other In The Novels The Adversary And The Prisonner}

\begin{abstract}
The relationship between Me and the Other is a subject which has been examined throughout the history of ideas in many aspects particularly social, political and legal. While "Me" was previously considered as the center of the thoughts on the subject, the concept "Other" has become a subject of study itself in philosophical and literary field, especially since the nineteenth century, owing to Hegel's Master-Slave Dialectic. The studies on relationship between $\mathrm{Me}$ and the Other have been intensified with the emergence of the phenomenological method in the early part of the 2oth century. Phenomenology studies the "phenomena": appearances of things, of realities in our experience, the way in which they appear directly in acts of consciousness. Through this method, many philosophers have taken in hand the relationship between Me and the Other via concepts such as "sameness/otherness", "immanence/ transcendence", "perception / sensation". The purpose of this study is to examine the relationship between Me and the Other in two novels of French Literature: Marcel Proust's The Prisoner and Emmanuel Carrère's The Adversary, through the thoughts of Husserl and Merleau-Ponty who are two important philosophers of phenomenological thinking. In this regard, we studied how the protagonists affect each other in the discourse of novels, how "Me", in other words the "Subject" perceives himself and the Other in this relationship and how he tries to approach to the Other. In this study, we aim to clarify how the relationship between Me and the Other was constructed in the discourse of novels by means of
\end{abstract}

$1 \quad \mathrm{Bu}$ makale XI. Ulusal Frankofoni Kongresi kapsamında 12 Mayı 2015 tarihinde Yıldız Teknik Üniversitesi'nde sunulan metnin genişletilmiş halidir.

$2 \quad$ Okt., İstanbul Üniversitesi Edebiyat Fakültesi Fransız Dili ve Edebiyatı, selda_bnkr@hotmail.com Adres $\mid$ Address 
A Phenomenological Outlook on The Relationship Between Me and The Other in The Novels The Adversary and The Prisonner / S. Bankır (p. 11-17)

phenomenological concepts of Husserl and Merleau-Ponty such as consciousness, perception, sensation and body.

Keywords: Me, other, phenomenology, novel, discourse

\section{Giriş}

Ben ve Öteki ilişkisi, 17. ve 18. yüzyıllardan itibaren felsefi tartışmaların içine giren, özellikle günümüz fenomenolojik çalışmalarının merkezinde yer alan konulardan biridir. Birey toplumsal bir varlık olarak sürekli ötekilerle etkileşim içindedir ve bu durum Ben'in varoluşsal sürecinde değişim ve yeni oluşumları meydana getirir. Ben ve Öteki ailevi, siyasi, dini, etnik, profesyonel vb. birçok boyutta kurdukları sosyal ilişkiler aracılığıyla, karşılıklı olarak birbirlerini belirler ve bu belirleyicilik onları birbirine bağlar.

Edmund Husserl ve Maurice Merleau-Ponty öne sürdükleri farklı fenomenolojik yaklaşımlarla Ben ve Öteki ilişkisini geliştiren en önemli 20. yüzyll düşünürlerindendir. Söz konusu düşünürlerin konuyla ilgili çalışmalarının merkezini Ben’in, diğer bir deyişle öznenin "Öteki deneyimi” oluşturur.

Fenomenoloji (Görüngübilim) 20. yüzyılda ortaya çıkan, birçok çağdaş düşünür tarafindan yaygın olarak kullanılan, sosyoloji ve psikoloji gibi diğer disiplinleri de etkileyen bir felsefe methodolojisidir. Çalışmamızda görüşlerini ele aldığımız Husserl ve Merleau-Ponty'nin yanı sıra, varlık ve zaman anlayışıyla Heidegger, varoluşçu düşüncesiyle Sartre ve etik felsefesiyle Levinas fenomenolojik yönteme başvuran diğer önemli düşünürlerdendir. 20. yüzyll düşünce tarihine yön veren bu önemli düşünürlerin çalışmaları, fenomenolojik yöntemin bu dönemde ne kadar etkin bir rol oynadığını göstermektedir.

Fenomenoloji etrafımızdaki fenomenlerin, yani algılanabilir ve deneyimlenebilir olay ve nesnelerin algımızda nasıl belirdiğini betimlemeyi amaçlayan bir yöntemdir. Fenomenolojik bakışa göre gerçeklik hiçbir zaman kendi halinde bulunmaz, ona sadece bilinç ve algı yoluyla ulaşlabilir. Günlük hayata dair deneyimleri inceleyen bu bilim, diğer felsefe akımları gibi özne nesne ilişkisini konu alır ve tüm dünya deneyimlerinin bilinç tarafından kurulduğunu öne sürer. Deneyim nesnesinin var oluşundan çok öznenin onu zihninde nasıl kurduğunu ön plana alan bu yöntemde, bilincin algı sırasındaki bilişsel süreçlerinin incelenmesi söz konusudur.

\section{Husserl ve Benzeştirici Algı}

Özgün bir felsefi yaklaşım olarak fenomenolojiyi öne süren ilk kişi alman filozof Edmund Husserl'dir. Husserl'in algllama deneyimi üzerine düşüncesini oluşturan en önemli kavramlar "bilinç" ve "yönelimsellik"tir. Düşünüre göre "bilinç daima bir şeyin bilincidir" (Husserl, 1953: 35) ${ }^{3}$, dolayısıyla yönelimseldir. Her bilinç eylemi daima kendisi dışındaki nesne ve olaylara yönelir. Husserl kendi fenomenolojik yöntemini bu "yönelimsellik" fikrine dayandırır ve çalışmalarında özne - nesne ilişkisini bu eksende yeniden ele alır.

Husserl’in çalışmalarındaki odak noktası dünyanın varolduğunun bilincine nasıl ulaşabileceğimizdir. Bu amaçla çevremizde bulunan nesne ve olguların bilincimizde nasıl şekillendiği sorusu üzerine yoğunlaşır. Bu çerçevede düşünürün ele aldığı diğer bir konu da Öteki sorunsalıdır. Husserl Öteki’nin öznenin bilincinde diğer nesnelerden nasıl ayrıldığını, nasıl başka bir özne, bir alter-ego olarak ortaya çıktığını göstermeye çalışır.

Düşünüre göre Ben Öteki'yle karşılaştığında onun özelliklerine doğrudan ulaşamaz. Özne Öteki'nin duygu ve düşüncelerine ancak bedeni aracılığılla ulaşabilir. Bedenlerinin benzerliği aracılığıyla, Ben Öteki’ni kendine benzer bir varlık olarak algılar ve diğer nesnelerden ayırır.

\footnotetext{
$3 \quad$ Kitaptan yapılan alıntı tarafımdam çevrilmiştir. 
Rakip ve Mahpus Romanlarında Ben ve Öteki İlişkisine Fenomenolojik Bir Bakış / S. Bankır (11-17. s.)

Husserl bu dưrumu Ben ve Öteki arasındaki "benzeştirici algı" (Husserl, 1953: 91)4 olarak ifade eder. Özne kendi davranışlarıyla Öteki'nin davranışları arasındaki benzerlikleri algılamaya çalışarak Öteki hakkında bir yoruma varır.

Husserl özellikle Ben ve Öteki arasındaki empati ilişkisi üzerinde durur. Filozofa göre empati yöntemi sayesinde Öteki'ne bir anlam verilebilir. Empati Öteki'ni onun kimlik alanında deneyimlememizi sağlar. Bu yöntemle onun psişik dünyasında var oluruz. Empati sırasında, Özne Öteki'yle ortak bir hareket, bir duyumsama, bir algı ya da bir amaç gibi birçok paylaşım içinde bulunur.

Empati sürecinde bilinçte hayali bir temsil söz konusudur. Eğer onun yerinde olsaydım ne hissederdim, hangi ruh halinde olurdum düşüncesi hâkimdir. Dolayısıyla hayal gücü ve duyumsama bu aktivitenin temel öğelerini oluşturur. Kendimi Öteki'nin konumunda hayal etmek aslında kendi yaşanmışlıklarımın değişime uğraması gibidir, diğer bir deyişle kurgusal bir Ben söz konusudur.

Husserl'in Öteki’ni anlamak için önerdiği empati yönteminin bir örneğini Çağdaş Fransız edebiyatı yazarlarından Emmanuel Carrère'in Rakip adlı eserinde görebiliriz. Carrère 1999 yılında kaleme aldığı kitabında, karısını, 2 çocuğunu, anne ve babasını öldüren Jean Claude Romand isimli bir adamın gerçeğe dayanan hikâyesini anlatır. Emmanuel Carrère gazeteden okuyarak öğrendiği bu haberde çok sıradan gözüken bir adamın nasıl böyle korkunç cinayetler işlediğini merak eder. Olayın nasıl olduğunu anlamak ve öğrendiklerini sonradan kitaplaştırmak için suçluyla iletişime geçer ve yaşadıklarını kitabında anlatır.

Kitapta aktarılan cinayetleri işleyen Jean Claude Romand on sekiz yaşından beri, yaklassık yirmi yıl boyunca, ailesine, arkadaşlarına, çevresindeki herkese yalan söyleyen bir adamdır. Herkes onu dünya çapında araştırmalar yapan, yoğun iş seyahatleriyle meşgul, önemli bir tıp adamı zannetmektedir. Oysa toplumdaki bu mükemmel görüntüsü tamamen bir hayal ürünüdür. Her ayrıntısını detaylı bir şekilde kurguladığı bu göstermelik üst düzey yaşamı dolandırıcılık yaparak sağlamaktadır. Romand günün birinde karısı ilk yalanını yakaladığında her şeyin ortaya çıkacağından korkup, onlarla yüzleşme duygusunu kaldıramayacağını düşünerek en yakınlarını öldürür. Görülen dava sonucu ömür boyu hapis cezasına çarptırılır.

Emmanuel Carrère'in kitabında, katilin bu cinayetleri neden ve nasıl işlediğinin yanı sıra özellikle yazarın bu olayı yazma sürecine tanıklık etmekteyiz. O dönem olayı öğrenen tüm insanlar katile karşı doğrudan bir nefret duygusuyla yaklaşırken, yazar olaya objektif bir şekilde, yargllamadan yaklaşmayı dener ve katilin bu cinayetleri işlemeye iten duygu ve düşüncelerini anlamaya çalışır. Yazar bu konudaki düşüncelerini şu şekilde ifade eder:

\begin{abstract}
"Romand'ın zimmetine para geçirmesi, zaman içinde kendine nasıl bir sahte yaşam kurduğu, filanca kişinin bundaki rolü, evet tüm bunları en uygun zamanda öğrenmem bana esas bilmek istediklerimi öğretmeyecekti: herkesin onun büroda olduğunu varsaydığı zamanlarda gün boyu aklından neler geçiyordu; ... son tahminlerde ileri sürdükleri gibi günlerini ormanda yürüyerek mi geçiriyordu? [...] Bu soru beni bir kitap yazmaya zorluyordu" (Carrère, 2000: 26).
\end{abstract}

Alıntıda görmüss olduğumuz yazarın katille ilgili merak ettiği "aklından neler geçiyordu" sorusu Husserl'in öne sürdüğü empati yönteminin temel noktalarından birini oluşturmaktadır. Emmanuel Carrère’i bu yöntemi kullanmaya iten ise yazmak istediği kitabında olayları 1. şahsın, yani katilin ağzından anlatmak istemesidir. Bu nedenle yazarın ulaşmak istediği olayların nasıl olduğu değil, katilin aklından geçenlerdir.

Carrère bir yandan katilin dava sürecini takip ederken bir yandan da onunla iletişime geçmeyi başarır. Tüm yaşadıklarını Romand'ın kendisinden öğrenir ve onu bu sürece getiren

\footnotetext{
$4 \quad$ Kitaptan yapılan alıntı tarafımdam çevrilmiştir. 
A Phenomenological Outlook on The Relationship Between Me and The Other in The Novels The Adversary and The Prisonner / S. Bankır (p. 11-17)

etkileri anlamaya çalışır. Romand'ın anlattıklarından yola çıkan yazar, onun psişik dünyasına girebilmek için onunla empati kurmayı dener; ancak fenomenolojik olarak bakıldığında, Romand yazar karşısına çözümlenmesi hayli zor bir Öteki olarak çlkar. Bunun nedeni ise söz konusu Öteki'nin katil olmasının empati sırasında minumum da olsa deneyimlenmesi gereken Öteki'yle benzeşme durumunu zorlaştırmasıdır.

Yazar katille ortak bir paylaşım zemini bulabilmek için öncelikle onun yaşadığı yerleri görmek ister. Detaylı bir şekilde onun hayat hikâyesini öğrenirken, tüm bu yaşanmışlıkları kafasında canlandırabilmek için katilin çocukluğunun, gençliğinin geçtiği, olaydan önce yaşamını sürdürdüğü yerleri gezer ve onun bakış açısından pozisyon almaya çalışır.

\begin{abstract}
“Onun yaşadığı yerlere yaptığım ilk yolculuktan kalan en belirgin anı bu. [...] Günleri tek başına geçirmenin nasıl olduğunu bilirim: insanın yatıp tavanı seyrettiği saatler, var olmama korkusu. Arabasının içinde neler hissedebileceğini düşünüyordum. Keyif mi? Çevresindekileri böylesine ustaca aldatmaktan kaynaklanan zafer mutluluğu mu? Eminim ki, hayır. Kaygı mı? Tüm bunların nasıl sona ereceğini, gerçeğin nasıl ortaya çıacağını ve daha sonra neler olacağını gözünün önüne getiriyor muydu? Alnını direksiyona dayayıp ağlıyor muydu? Yoksa hiçbir şey hissetmiyor muydu? Yoksa böylesine yapayalnız, hiçbir şey düşünmeden, hissetmeden, araba kullanan, yürüyen, okuyan bir makine, uyuşmuş ve posası çıkmış bir Doktor Romand'a mı dönüşüyordu yavaş yavaş ?” (Carrère, 2000: 76, 77).
\end{abstract}

Alıntıda Özne konumundaki yazarın Öteki konumundaki suçluyla bilişsel ve duyusal olarak nasıl ortak bir paylaşım içine girmeye çalıştığını görüyoruz. Yazar, her gün evden işe gidiyorum diye çıkan ve tüm gününü yalnız geçiren Romand'ın neler hissettiğini ve neler düşündüğünü anlamaya çalışır; bunun için de öncelikle onunla ortak bir benzerlik noktası bulur: "Günleri tek başına geçirmenin nasıl olduğunu bilirim.” Bu geçiş sürecinden sonra da Öteki’nin neler yaşayp hissettiğini, nasıl hareket ettiğini birden fazla hayali senaryoyla kafasında kurmaya ve tahmin etmeye çalışır.

Kitabın ilerleyen bölümlerinde Carrère’in katille yaptığı yazıșmalar, ulaştığı psikiyatr raporları ve gerçekleştirdiği empati denemeleri aracılığıyla katili bu cinayetleri işlemeye götüren süreci anlamaya başladığını görürüz.

"Yıllarca süren o sahtekârlığın benim gözümde hiçbir esrarlı yanı yoktu artık, sadece körlük, umutsuzluk ve korkaklığın acıklı bir karışımıydı. Otoyollar üstündeki dinlenme istasyonlarında ya da kafeteryaların park yerlerinde geçen o boş saatler boyunca kafasından geçenleri artık biliyordum, ben de kendimce onu tanımıştım, artık ilgi alanıma girmiyordu" (Carrère, 2000: 171).

Alıntıda görüldüğü üzere yazar, katilin umutsuzluk, korkaklık ve psikolojik bozukluklardan oluşan iç dünyasına merakını giderecek düzeyde ulaşmayı başarır. Romand mitomani, yani yalan söyleme hastasıdır. Bu psikolojik bozukluk onun kendisine tutarlı ve gerçek bir kimlik oluşturmasını engellemektedir. Romand'ın sağlıksız bir bilince sahip olduğunu anlayan yazar, kitabında olayları anlatırken kullanacağı bakış açısını değiştirmeye karar verir ve bunun sebebini de Romand'a yazdığı mektupta şu şekilde açıklar:

\begin{abstract}
"Aslında sizin içinizde var olan ruhsal ve zihinsel çatışma benimkinden daha zor: benliğinizi tam olarak kavrayamamanı, sizin "ben" demenizi engelleyen ve giderek büyüyen o derin boşluk. Sizin adınıza "ben" demek elbette bana düşmez, bu durumda bana yapacak tek şey kalıyor; sizin hakkınızda kendim için "ben" diyorum. [...] Tamamen kendi adıma sizin öykünüzde beni etkileyen ya da kendi yaşamımda yankılar yaratan yönleri anlatmak istiyorum" (Carrère, 2000: 160).
\end{abstract}

Carrère’in, kitabını yazarken olayları Öteki'nin yerine "Ben" diyerek anlatma isteği, katilin tutarlı bir bilinç yapısına sahip olamaması, kendisinin bile "Ben" diyememesi nedeniyle kesintiye uğrar. Kendi içinde zihinsel çatışma yaşayan öteki bir bilince ulaşmanın zorluğunu 
anlayan yazar, olayları katilin gözünden değil de kendi bakış açısıyla anlatmaya karar verir ve sonuç olarak kitapta olayların gelişiminden çok kendi yazma sürecini aktarır. Carrère’in karşısındakini anlamaya odaklı bu yazım serüveni aracılığıyla, Husserl’in öne sürmüss olduğu Öteki'ne ulaşma sürecinde rol oynayan "benzeştirici algı"nın gerekliliğini bir kez daha görmüş oluruz.

\title{
Merleau-Ponty ve Tenselleşmiş Algı
}

Fenomenolojik yöntemin diğer önemli isimlerinden biri de Maurice Merleau-Ponty'dir. Husserl'in düşünceleri tarafindan etkilenen düşünür, tüm bilinç eylemleri içerisinde en önemlisinin, dünyayla bağlantı kurmamızda ilk rolü oynayan "algı" olduğunu savunur. Merleau-Ponty ortaya koyduğu felsefeyle öznenin dünya deneyimini "algı" ve "duyumsama" ekseninde yeniden ele alır.

Düşünürün ele aldığı bu deneyimde "beden" dünyaya yönelmiş olan bir algı ve duyumsama alanı olarak belirir. Ona göre algı deneyimi sadece bilişsel değildir. Beden öznel ve duyusal deneyimin merkezi olarak algıda önemli rol oynar. Bu anlamda algı somutlașmış ve tenselleşmiştir, çünkü bedene bağlıdır. Bedeni "dünyada olmanın aracı" (Merleau-Ponty, 1945: 97)5 olarak gören Merleau-Ponty öznenin algı deneyimini incelemek için yeni bir beden ve anlam felsefesi geliştirir.

Düşünürün Öteki’ni algılamamızla ilgili görüşlerini incelediğimizde ise yine beden ve duyumsama üzerinde durduğunu görürüz. Merleau-Ponty dünyaya ve diğerlerine açılmamızı sağlayan bağı diyalog, kavrama, duyumsama ve arzudan oluşan bir ilişkiler ağı olarak belirler. Öteki'yle olan iletişim özellikle Ben'in kendini tanımasında önemli rol oynar. Merleau-Ponty'e göre "kendimizle olan iletişimimiz her zaman bir kültür aracıllğıyla, özellikle dışarıdan edindiğimiz ve bizi kendimizi tanımaya yönelten dil aracılı̆̆gyla gerçekleşir" (Merleau-Ponty, 2002: 49) ${ }^{6}$. Dolayısıyla diyalog Öteki'ne açılmamızı sağlayan ve bu etkileşim sonunda yine kendi farkındalığımıza döndüğümüz bir araç olarak ortaya çıkar.

Merleau-Ponty çalışmalarında Husserl'in "yönelimsellik" kavramını geliştirir ve tensel bir yönelimsellik üzerinde durur. Ona göre öznenin dünyayla ve ötekilerle etkileşimini sağlayan tensel bir yönelimselliktir ve bu yönelimselliğin temelinde arzu ve duyumsama yer alır. Özellikle "arzu” kavramı Öteki'yle olan ilişkiyi canlı tutarak benim bedenim ile Öteki'nin bedeni arasındaki bağı oluşturur.

Marcel Proust'un Kayıp Zamanı İzinde adlı eserinin 5. kitabı olan Mahpus adlı romanda Merleau-Ponty'nin Öteki’ne ulaşmayla ilgili düşüncelerinin bir örneğini görebiliriz. Proust romanında, tutkuyla bağlı olduğu bir genç kızı evinde alıkoyan bir adamın kafasından geçenleri ve yaşadıklarını anlatır.

Romanda özne rolüyle beliren Marcel adlı kahraman sürekli olarak, birlikte olduğu Albertine'e karşı olan duygu ve düşüncelerinin seyri içindedir. Anlatı öznenin Öteki’ne karşı saplantıya varan tutkusu etrafında oluşur. Romanda Ben’in Öteki’ne yönelimini sağlayan, Merleau-Ponty'nin çalışmalarında ileri sürdüğü gibi ona karşı duyduğu arzudur. Albertine romanda Marcel için sürekli elde tutulması gereken bir arzu nesnesi olarak belirir.

\begin{abstract}
"Albertine'in benim evimde yaşamasından aldığım haz, olumlu bir hazdan çok, çiçek açmıș bir genç kızı, herkesin sırayla gelip onu koklayabileceği toplumdan koparmıș olmanın, beni çok mutlu etmese de, başkalarını hiç mutlu edememesinin hazzıydı. Hırs, şan, şeref beni hiç ilgilendirmiyordu. Ayrıca nefret duygusundan da tamamıle yoksundum. Buna rağmen, tensel aşk, onca rakip üzerinde bir üstünlük sağlamış olmanın hazzı demekti benim için. Ne kadar tekrar etsem azdır, her şeyden çok da bir yatışmaydı" (Proust, 2008: 74).
\end{abstract}

\footnotetext{
$5 \quad$ Kitaptan yapılan alıntı tarafımdam çevrilmiştir.

$6 \quad$ Kitaptan yapılan alıntı tarafımdam çevrilmiştir.

Kurklareli Üniversitesi, Fen Edebiyat Fakültesi, Türk Dili ve Edebiyatı 
A Phenomenological Outlook on The Relationship Between Me and The Other in The Novels The Adversary and The Prisonner / S. Bankır (p. 11-17)

Alıntıda görüldüğü gibi öznenin Öteki’ne karşı duyduğu "tensel aşk" doğrudan bedenle, temasla ilgilidir. Beden Öteki'yle kurulan bağın, hissedilen arzunun temellendiği yerdir. Albertine’i elde tutulması gereken bir değer nesnesi olarak gören Marcel’in duyduğu mutluluk onunla yaşadığı duygusal bir paylaşımdan çok, ona fiziksel olarak sahip olmaktan ileri gelmektedir.

Anlatı boyunca kahraman Albertine’in fiziksel varlığının kendi üzerinde yarattığı duygu durumlarını betimler. Albertine kendisinden ayrı olduğu zamanlarda Marcel'in ruh haline tam bir kargaşa hâkimken, genç kadının varlığı ona huzur ve rahatlama vermektedir. Bu durum Marcel’in evini paylaştı̆̆ 1 Albertine’in tüm hareketlerini kontrol etme saplantısına kadar varır.

"Hiç şüphesiz, sahip olmak için arzu etmiş olmak şarttır. Bir çizgiye, bir yüzeye, bir hacme, ancak aşkımız oraya yerleşmişse sahip olabiliriz” (Proust, 2008: 171).

Kahramanın Albertine'e karşı hissettiği sahip olma tutkusunu ifade ettiği bu cümleler fenomenolojik olarak baktığımızda öznenin nesnesine sahip olmak için arzu ekseninde yöneldiğini göstermektedir. Romandaki bir başka bölüm ise Merleau-Ponty'nin öne sürdüğü gibi beden, zihin ve duyuların ne kadar iç içe bir yapı sergilediğini ortaya koyar niteliktedir.

"Gözlerimin, dudaklarımın ve ellerimin hayal gücü Balbec'te Albertine’in bedenini öylesine kuvvetle biçimlendirmiş, şefkatle parlatmıştı ki, şimdi bu arabada o bedene dokunmak, onu sarmalamak için Albertine’i kucaklamama hatta görmeme gerek yoktu; ... iç içe geçmiş duyularım onu olduğu gibi sarmalıyordu. [...] Albertine kapıdan içeri girerken bakışlarımla hala onu sarmalamaktaydım" (Proust, 2008: 171- 172).

Alıntıda öznenin Öteki’yle kurduğu ilişkide çeşitli duyu deneyimleriyle algısını zenginleştirdiğini ve bu deneyimlerine duygu durumunun yön verdiğini gözlemleriz. Marcel'in Albertine'e karşı hissettiği arzunun yoğunluğu onun duyum ve algı sürecini doğrudan etkilemektedir. Fenomenolojik olarak öznenin arzu nesnesine bilincinde nasıl ulaştığına baktığımızda, tüm hayal gücünün farklı duyuları birleştirerek tek bïr duyu, "dokunma" üzerinde yoğunlaştığını görürüz. Tüm duyular içerisinde özneye Öteki’nin varlığını hissettiren en güçlü duyu dokunma olarak belirir.

Öte yandan Marcel ve Albertine arasındaki ilişki, Merleau-Ponty'nin kendimizle ilgili düşüncelerimizin daima ötekilerle olan ilişkimize bağlı olduğunu belirttiği fikirlerini doğrular niteliktedir. Romanın sonuna doğru Marcel, Albertine'le yaşadığı ilişki sonucu kendisiyle ilgili deneyimlediği algısal dönüşümünü şu şekilde ifade eder:

\begin{abstract}
"Evde beni karşılayacak olan kişi, kendi şahsımı bütünüyle ellerine teslim ettiğim şahıstı; kendimi düşünecek serbest bir ânım bile yoktu [...] Az sonra içerisine gireceğim odanın penceresine dışarıdan, aşağıdan son bir kez baktığımda... kendi ellerimle şekillendirdiğim ve ebediyen içinde hapsolacağım ışıklı bir kafes görür gibi oldum” (Proust, 2008: 328).
\end{abstract}

"Eve bir mahpusla buluşacağım düşüncesiyle değil, kendim mahpus olduğum düşüncesiyle dönmüştüm” (Proust, 2008: 344).

Romana adını veren "mahpus" kavramı anlatının başında Albertine karakterini nitelemektedir. Marcel koyduğu sıkı kurallar ile aynı evde yaşadığı Albertine üzerinde tam bir kontrole sahiptir. Ancak alıntılarda görüldüğü gibi romanın ilerleyen bölümlerinde durum tersine döner. Albertine'e karşı duyduğu tutku ve kıskançlık Marcel'e hükmetmeye başlar. Tamamen denetim altında tutamadığı Albertine, sahip olunamayan Öteki konumunda hissettirdikleriyle öznenin kendiyle ilgili olan algısının değişmesine, içsel bir dönüşüm yaşamasına neden olur. Bu durum Ben ve Öteki’nin ilişkilerinde karşılıklı olarak birbirleri üzerinde nasıl belirleyici bir nitelik taşıdığını bir kez daha gösterir. 


\section{Sonuç}

Gerçekleştirdiğimiz çalışmada, Emmanuel Carrère'in Rakip ve Marcel Proust'un Mahpus adlı romanlarının söyleminde Ben ve Öteki ilişkisinin nasıl oluştuğunu Husserl ve MerleauPonty'nin fenomenolojik düşüncelerinden yola çıkarak incelemeye çalıştık. Bu doğrultuda, romanlardaki başkahramanların ötekilerle iletișim kurarken beliren bilișsellik, algı ve duyumsama durumlarının oluşum ve değişim süreçlerini gözlemledik. Carrère’in romanında öznenin Öteki’ne yaklaşımı Husserl'in önermiş olduğu bilinç merkezli empati yönetimine dayanırken, Proust'un romanında kahramanlar arasındaki ilişkinin daha çok MerleauPonty'nin öne sürdüğü gibi duygu ve duyumsama durumları etrafında șekillendiğini görmekteyiz. Bununla birlikte, romanlarda bedenin farklı işlevlerle de olsa Öteki'ne ulaşmada önemli rol oynadığını söyleyebiliriz. Rakip romanında beden, empati sırasında Ben ve Öteki arasındaki benzerlik işleviyle ortaya çıkarken, Mahpus romanında algıyı zenginleştiren bir unsur, duyumsamanın merkezi olarak belirir. Sonuç olarak romanların söyleminde bilinç, algı, duyumsama ve beden öznenin Öteki’ne ulaşmasını sağlayan farklı yapılar olarak ortaya çıkmaktadır.

\section{Kaynakça}

Carrère, E. (2000). Rakip. İstanbul: Doğan.

Husserl, E. (1953). Méditations cartésiennes. Introduction à la phénoménologie. Traduit de l'allemand par Gabrielle Peiffer et Emmanuel Levinas. Paris: Librairie Philosophique J. Vrin.

Merleau-Ponty, M. (1945). La phénoménologie de la perception. Paris: Gallimard.

Merleau-Ponty, M. (2002). Causeries (entretiens radiophoniques de 1948). Paris: Le seuil.

Proust, M. (2008). Mahpus. İstanbul: Yapı Kredi. 